\title{
Attenuation of the association between sugar-sweetened beverages and diabetes risk by adiposity adjustment: a secondary analysis of national health survey data
}

\author{
Yi Jing ${ }^{1} \cdot$ Thang S. Han ${ }^{2,3} \cdot$ Majid M. Alkhalaf ${ }^{1} \cdot$ Michael E. J. Lean ${ }^{1}$
}

Received: 31 October 2017 / Accepted: 9 May 2018 / Published online: 15 May 2018

(c) The Author(s) 2018

\begin{abstract}
Purpose While weight gain and obesity are the dominant factors, dietary sugar and specifically sugar-sweetened beverages (SSB) has been implicated in causing type 2 diabetes (T2DM). We assessed how much of the apparent effect of SSB is explained by adiposity, but not captured by adjustment for BMI, which is a poor index of body fat.

Methods We examined data from 5187 adults (mean age 50.8 years, $\mathrm{SD}=16.4,172$ (3.3\%) T2DM), from the Scottish Health Survey 2003 and 2008-2010 databases. Logistic regression was used to assess the association between SSB consumption and T2DM (non-insulin treated) and its attenuation (reduction in odds ratios, ORs), after entering published anthropometric indices of adiposity into the regression model, adjusted for age, sex, social class, education, smoking, alcohol consumption and physical activity.

Results Compared with low SSB categories ("less often/never", once/week or 1-3 times/month), the OR without adiposity adjustment for having T2DM in high SSB consumers ( $2-3,4-5, \geq 6 /$ day) was 2.56 (95\% CI $1.12-5.83 ; p=0.026)$. That OR was marginally changed by adjusting for BMI $(+4.3 \%)$, WC $(+5.5 \%)$ or total body fat $(-4.3 \%)$, but greatly attenuated by adjusting for estimated \%body fat $(-23.4 \%)$. These indices had similar influences on the associations between SSB and T2DM combining known T2DM patients with unknown $\mathrm{HbA}_{1 \mathrm{c}}>6.5 \%,>48 \mathrm{mmol} / \mathrm{mol}$.

Conclusions Associations between SSB and T2DM are attenuated more markedly by adjustment with estimated \%body fat than with BMI, indicating an adiposity effect not captured using BMI. Future research should employ best available estimates of adiposity.
\end{abstract}

Keywords BMI $\cdot$ Obesity $\cdot$ Health survey $\cdot \mathrm{HbA}_{1 \mathrm{c}} \cdot$ Nutrition $\cdot$ Sucrose

\section{Introduction}

The global prevalence of adult type 2 diabetes mellitus (T2DM) has nearly doubled from $4.7 \%$ in 1980 to $8.5 \%$ (422 million cases) in 2014, coinciding with trends in obesity and overweight [1]. The burden of diabetes was found

Michael E. J. Lean

mike.lean@glasgow.ac.uk

1 Human Nutrition, School of Medicine, University of Glasgow, Level 2, New Lister Building, 10-16 Alexandra Parade, Royal Infirmary, Glasgow G31 2ER, Scotland, UK

2 Institute of Cardiovascular Research, Royal Holloway, University of London, Egham, UK

3 Department of Endocrinology, Ashford and St Peter's NHS Foundation Trust, Chertsey, UK strongly attributable to overweight and physical inactivity by comparative risk assessment [2]. Furthermore, T2DM has now been proven to be preventable, with body weight control being the dominant factor, with lesser influences from physical activity, and more minor dietary factors such as reducing saturated fats, increasing fruit and vegetables, magnesium and dietary fibre [3-5].

For historical reasons and through limited understanding of nutrition, a direct association has been assumed by many between raised 'blood sugar' and dietary sugar [5]. Ecological data support an association (not necessarily causal) between average sugar use and diabetes prevalence [6], but the relationship is potentially confounded by more frequent overweight and obesity in countries with more diabetes: attempting to correct this for average BMI will not remove the influence of fatness, as BMI correlates rather weakly with body fat [7]. Obtaining reliable quantitative 
data on total dietary intake of individuals, from which to estimate sugar consumption, is not possible because overweight and obese individuals (who must have relatively high energy consumptions to remain overweight) are well known to under-report total food consumptions systematically [8, 9]. However, reported consumptions of specific foods and drinks, such as sweetened beverages, are considered more reliable because their consumption patterns are more stable [10]. Sugar-sweetened beverages (SSB) have come under particular scrutiny in relation to diabetes because they provoke a high blood glucose peak, and because calories in liquid have a weaker effect on satiety than in solid form [11].

A large recent study by Imamura et al. found BMI marginally attenuates the association between SSB consumption and T2DM [12], but neither this nor any previous population-based studies have investigated measurements or estimates of body fat itself as a confounding factor which might be responsible for this association. The present study was conducted to establish the extent to which the association between SSB intake and T2DM is attenuated by commonly used indices of adiposity including BMI, waist circumference (WC), and estimates of total adipose tissue mass (TATM) and percent body fat (BF\%).

\section{Methods}

\section{Data source}

This study combined available datasets of Scottish Health Surveys 2003, 2008, 2009 and 2010 [13] and used 'complete cases' of individuals for whom the necessary data were collected to be able to compare all the adiposity indices. The whole survey program comprised a household survey and an individual survey, among a total of 38,863 free-living participants elected from electoral registers to be nationally representative. Those under 18 years old at last birthday, pregnant, and on insulin treatment (potentially cases of T1DM, or T2DM with secondary weight gain) were all excluded $(n=10,734)$ leaving 28,136 participants. For 6358 of these participants after exclusions, nurse-led interviews were conducted using standard questionnaires to collect information on the participants' sociodemographic characteristics and lifestyle variables, providing measured anthropometric data and blood samples for glycated haemoglobin $\left(\mathrm{HbA}_{1 \mathrm{c}}\right)$.

Physical activity level was assessed from reported number of days per week with any physical activities lasting $\geq 30$ or 10-29 min of exercise sessions and categorised into groups of none (physical inactivity), active $<1$ day/week, 1 or 2 days/week, 3 or 4 days/week and $\geq 5$ days/week. Smoking status was defined as never smoker, used to smoke occasionally, used to smoke regularly and current smoker. Alcohol consumption was defined according to frequency of drinking: never-drinkers, drinking once or twice/year, once every couple of months, once or twice a month, once or twice a week, 3 or 4 times/week, 5 or 6 times/week and almost every day. Education level attainment was grouped into other school level or no qualifications, standard grade or equivalent, higher grade or equivalent, higher national certificate/diploma or equivalent and degree or higher. Socioeconomic classes were determined from occupation and classified as unskilled manual, semi-skilled manual, skilled manual, skilled non-manual, managerial technical and professional [13].

\section{Sugar-sweetened beverage intakes}

During interviews, SSB consumption frequency (without volume) of soft drinks was recorded as "less often or never", 1-3 times per month, 1, 2-4, 5-6 times per week, 1, 2-3, $4-5, \geq 6$, times per day, which were categorised from 1 to 9 respectively for analysis.

\section{Diabetes cases and $\mathrm{HbA}_{1 \mathrm{c}}$}

A previous diagnosis of diabetes by doctors was recorded. Among those without previous diagnosis of T2DM, those who had $\mathrm{HbA}_{1 \mathrm{c}}>6.5 \%(48 \mathrm{mmol} / \mathrm{mol})$ were added to the diagnosed T2DM group, in a second model.

\section{Indices of adiposity}

Four established indices of adiposity were assessed, to test their effect on the association between SSB and diabetes: BMI $\left(\mathrm{kg} / \mathrm{m}^{2}\right)$, WC $(\mathrm{cm})$, total adipose tissue mass [TATM $(\mathrm{kg})$ ] calculated using equation derived by Al-Gindan et al. [14] which contains body weight and height for both sexes, plus WC for male and age for female, and BF\% (\% of body weight) using equation derived by Lean et al. [7] which contains WC and age for both sexes.

\section{Statistical analysis}

From 28,136 participants we extracted 5187 cases with complete data for all variables of interest, (i.e. 22,949 with incomplete data or did not meet inclusion criteria were excluded). There were no important differences between the extracted and excluded groups in gender distribution $(\mathrm{M} / \mathrm{F}=54.8 / 45.2$ vs. $55.5 / 44.5 \% . p=0.176)$, mean age (50.8 vs. 50.3 years, $p=0.093$ ) or BMI (27.5 vs. $27.8 \mathrm{~kg} /$ $\left.\mathrm{m}^{2}, p<0.05\right)$. Predictor variables were categorised into three categories: For SSB, category 1-3 indicates lowest drinking frequency of "less often or never", 1-3 times/month or once/week; category 4-6 indicates drinking frequency of 2-4 or 5-6 times/week or once/day, and category 7-9 indicates highest drinking frequency of $2-3,4-5$ or $\geq 6$ / 
day. Chi-square test was used to assess differences in T2DM prevalence across different categories of SSB and adiposity and logistic regression to assess the association between SSB and previously diagnosed T2DM. Indices of adiposity were individually entered into the logistic regression model to examine the degree in which this association was affected, indicated by changes in odds ratios (ORs). Analysis was repeated with the addition of cases without previous diagnosis of T2DM but with $\mathrm{HbA}_{1 \mathrm{c}}>6.5 \%$ (48 mmol/mol). Data were adjusted for age, sex, social class, smoking status, alcohol consumption, education attainment and physical activity level. Analyses were performed using SPSS V.22.0 (SPSS Inc, Chicago, IL, USA). Statistical significance was accepted when $p<0.05$.

The influences of adiposity on the association between SSB and T2DM were expressed as percentage reduction from $100 \%$, by dividing the "difference between OR after adjustment minus OR before adjustment for adiposity" over "OR before adjustment for adiposity".

\section{Results}

Men and women had similar mean age (51.1 and 50.5 years), BMI (27.6 and $27.4 \mathrm{~kg} / \mathrm{m}^{2}$ ) and $\mathrm{HbA}_{1 \mathrm{c}} 5.32 \%$ (34.7 mmol/ $\mathrm{mol})$ and $5.30 \%(34.4 \mathrm{mmol} / \mathrm{mol})$. Men had larger WC than women (by $10 \mathrm{~cm}, p<0.001$ ) while women had greater amount of TATM $(4.7 \mathrm{~kg}, p<0.001)$ and BF\% (11.6\% of body weight, $p<0.001$ ) than men (Table 1 ).

The prevalence of T2DM was $1.8 \%$ in men who had the lowest intake of SSB ("less often or never", once/week or 1-3 times/month), $1.3 \%$ in men who consumed between 2 and 4 or 5-6 times/week and once/day, and $4.9 \%$ in men who had the highest intake of SSB $(2-3,4-5, \geq 6$ per day) $\left(\chi^{2}=19.0, p<0.001\right)$; the respective values of T2DM prevalence across SSB categories for women were 1.7, 2.7 and $3.3 \%\left(\chi^{2}=2.8, p<0.242\right)$. A significantly greater prevalence of T2DM was observed for those in higher tertiles of all adiposity measures in both sexes (Table 2).

We found similar influences by these indices on the association between SSB and known T2DM patients combined with unknown T2DM who had $\mathrm{HbA}_{1 \mathrm{c}}>6.5 \%$ (48 $\mathrm{mmol} / \mathrm{mol})$.

Table 3 shows that compared with those with the lowest SSB intake ("less often or never", once/week or 1-3 times/month), OR for having T2DM in those with highest SSB intake (2-3, 4-5, $\geq 6 /$ day), without adiposity adjustment, was 2.56 (95\% CI $1.12-5.83, p=0.026)$. That OR was minimally changed by adjustment for BMI $(+4.3 \%)$, WC $(+5.5 \%)$ or total body fat $(-4.3 \%)$, while greatly attenuated by \%body fat $(-23.4 \%)$ (Fig. 1). There was a similar association between SSB and T2DM in the larger combined model, including known (diagnosed) $(n=172)$ with those previously undiagnosed but with $\mathrm{HbA}_{1 \mathrm{c}}>6.5 \%$ $(48 \mathrm{mmol} / \mathrm{mol})(n=230):$ OR $=1.93$ (95\%CI: $1.01-3.69$, $p=0.046$ ) (Table 4) and similar magnitude of changes in this association by indices of adiposity (Fig. 1).

We observed that $\mathrm{BF} \%$ had stronger associations than BMI with SSB $\left(\chi^{2}=27.0, p<0.001\right.$ vs. $\left.21.2 ; p<0.001\right)$ and with T2DM $\left(\chi^{2}=130.2 ; p<0.001\right.$ vs. 102.5; $p<0.001$ ). Among T2DM, we found that, compared with patients with $\mathrm{HbA}_{1 \mathrm{c}}<6.5 \%(48 \mathrm{mmol} / \mathrm{mol})$, more of those with $\mathrm{HbA}_{1 \mathrm{c}}>6.5 \%(48 \mathrm{mmol} / \mathrm{mol})$ had figures in the highest tertile of WC (26.6 vs. $\left.73.4 \%, \chi^{2}=8.2, p=0.016\right)$ and BF\% (25.6 vs. $74.4 \%, \chi^{2}=12.3, p=0.002$ ) but did not have significantly higher BMI $(p=0.253)$, TATM $(p=0.171)$ or SSB intake $(p=0.124)$.

We examined relationships between SSBs and $\mathrm{HbA}_{1 \mathrm{c}}$ in people who were not diabetic: the associations were trivial though statistically significant, and no effect was evident from adjustment for BMI, WC or BF\%. We also examined separately those who were not previously diagnosed with diabetes but had $\mathrm{HbA}_{1 \mathrm{c}}$ levels $>6.5 \%$ ( $>48 \mathrm{mmol} / \mathrm{mol}$ ).
Table 1 Subject characteristics including age, anthropometry, estimated skeletal and fat masses and percentages and $\mathrm{HbA}_{1 \mathrm{c}}$

\begin{tabular}{|c|c|c|c|c|c|c|c|}
\hline & \multicolumn{2}{|c|}{ Men $(n=2347)$} & \multicolumn{2}{|c|}{ Women $(n=2840)$} & \multicolumn{3}{|c|}{$\begin{array}{l}\text { Independent } t \text { test for group differences } \\
\text { (male values minus female values) }\end{array}$} \\
\hline & Mean & SD & Mean & $\mathrm{SD}$ & Mean & $95 \% \mathrm{CI}$ & $p$ \\
\hline Age (years) & 51.1 & 16.6 & 50.5 & 16.3 & 0.6 & $-0.3,1.5$ & 0.228 \\
\hline Weight (kg) & 83.6 & 14.5 & 70.6 & 14.3 & 13.0 & $12.2,13.7$ & $<0.001$ \\
\hline Height $(\mathrm{cm})$ & 174.0 & 7.1 & 160.6 & 6.7 & 13.4 & $13.0,13.8$ & $<0.001$ \\
\hline BMI $\left(\mathrm{kg} / \mathrm{m}^{2}\right)$ & 27.6 & 4.5 & 27.4 & 5.4 & 0.2 & $-0.1,0.5$ & 0.139 \\
\hline Waist (cm) & 97.1 & 11.9 & 87.1 & 13.0 & 10.0 & $9.3,10.7$ & $<0.001$ \\
\hline TATM (kg) & 24.6 & 8.1 & 29.3 & 11.0 & -4.7 & $-5.2,-4.1$ & $<0.001$ \\
\hline BF\% (\% body weight) & 28.4 & 7.4 & 40.0 & 7.4 & -11.6 & $-12.0,-11.2$ & $<0.001$ \\
\hline $\mathrm{HbA}_{1 \mathrm{c}}(\%)^{\mathrm{a}}$ & 5.32 & 0.49 & 5.30 & 0.47 & 0.02 & $-0.01,0.05$ & 0.153 \\
\hline $\mathrm{HbA}_{1 \mathrm{c}}(\mathrm{mmol} / \mathrm{mol})^{\mathrm{a}}$ & 34.7 & 5.3 & 34.4 & 5.2 & 0.2 & $-0.1,0.6$ & 0.153 \\
\hline
\end{tabular}

${ }^{\mathrm{a}} \mathrm{HbA}_{1 \mathrm{c}}$ in 1823 men and 2086 women who were not previously diagnosed with T2DM 
Table 2 Distribution of SSB, indices of adiposity and lifestyle factors in men and in women in patients with diagnosed T2DM and those with no previous T2DM diagnosis but with $\mathrm{HbA}_{1 \mathrm{c}}>6.5 \%(48 \mathrm{mmol} / \mathrm{mol})$

\begin{tabular}{|c|c|c|c|c|c|c|c|c|c|c|c|c|}
\hline \multirow[b]{3}{*}{ Categories of SSB intake and indices of adiposity ${ }^{a}$} & \multicolumn{6}{|c|}{ Men } & \multicolumn{6}{|c|}{ Women } \\
\hline & \multicolumn{3}{|c|}{$\begin{array}{l}\text { Diagnosed T2DM } \\
(n=85 \text { cases and } \\
2262 \text { non-cases })\end{array}$} & \multicolumn{3}{|c|}{$\begin{array}{l}\text { Diagnosed } \\
\text { T2DM+ no } \\
\text { previous T2DM } \\
\text { diagnosis with } \\
\mathrm{HbA}_{1 \mathrm{c}}>6.5 \% \\
(48 \mathrm{mmol} / \mathrm{mol}) \\
(n=114 \mathrm{cases} \text { and } \\
2233 \text { non-cases })\end{array}$} & \multicolumn{3}{|c|}{$\begin{array}{l}\text { Diagnosed T2DM } \\
(n=87 \text { cases and } \\
2753 \text { non-cases })\end{array}$} & \multicolumn{3}{|c|}{ 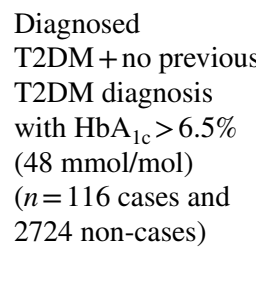 } \\
\hline & $\%$ & $\chi^{2}$ & $p$ & $\%$ & $\chi^{2}$ & $p$ & $\%$ & $\chi^{2}$ & $p$ & $\%$ & $\chi^{2}$ & $p$ \\
\hline SSB category $1-3$ & 1.8 & 19.0 & $<0.001$ & 3.2 & 12.8 & 0.002 & 1.1 & 2.8 & 0.242 & 1.7 & 2.9 & 0.236 \\
\hline SSB category 4-6 & 1.3 & & & 2.7 & & & 2.7 & & & 4.6 & & \\
\hline SSB category 7-9 & 4.9 & & & 6.1 & & & 3.3 & & & 4.2 & & \\
\hline BMI lowest tertile $\left(\mathrm{M}<25.48, \mathrm{~F}<24.47 \mathrm{~kg} / \mathrm{m}^{2}\right)$ & 1.3 & 40.3 & $<0.001$ & 1.9 & 46.8 & $<0.001$ & 0.7 & 63.4 & $<0.001$ & 1.2 & 81.0 & $<0.001$ \\
\hline BMI middle tertile $\left(\mathrm{M} \geq 25.48-, \mathrm{F} \geq 24.47 \mathrm{~kg} / \mathrm{m}^{2}\right)$ & 2.6 & & & 3.6 & & & 1.8 & & & 2.3 & & \\
\hline BMI highest tertile $\left(\mathrm{M} \geq 29.00, \mathrm{~F} \geq 28.88 \mathrm{~kg} / \mathrm{m}^{2}\right)$ & 7.0 & & & 9.0 & & & 6.7 & & & 8.8 & & \\
\hline WC lowest tertile $(\mathrm{M}<91.25, \mathrm{~F}<80.55 \mathrm{~cm})$ & 1.4 & 42.6 & $<0.001$ & 1.9 & 47.1 & & 0.5 & 53.5 & $<0.001$ & 0.7 & 80.9 & $<0.001$ \\
\hline WC middle tertile $(\mathrm{M} \geq 91.25, \mathrm{~F} \geq 80.55 \mathrm{~cm})$ & 2.3 & & & 3.6 & & & 2.4 & & & 2.8 & & \\
\hline WC highest tertile $(\mathrm{M} \geq 101.70, \mathrm{~F} \geq 91.15 \mathrm{~cm})$ & 7.1 & & & 9.0 & & & 6.2 & & & 8.6 & & \\
\hline TATM lowest tertile $(\mathrm{M}<26.52, \mathrm{~F}<37.01 \mathrm{~kg})$ & 0.7 & 48.9 & $<0.001$ & 1.3 & 62.4 & $<0.001$ & 1.3 & 40.3 & $<0.001$ & 1.3 & 43.4 & $<0.001$ \\
\hline TATM middle tertile $(\mathrm{M} \geq 26.52, \mathrm{~F} \geq 37.01 \mathrm{~kg})$ & 2.3 & & & 2.9 & & & 2.6 & & & 2.4 & & \\
\hline TATM highest tertile $(\mathrm{M} \geq 31.44, \mathrm{~F} \geq 43 \mathrm{~kg})$ & 6.1 & & & 8.1 & & & 7.0 & & & 7.2 & & \\
\hline BF\% lowest tertile $(\mathrm{M}<24.93, \mathrm{~F}<36.37 \%$ of weight $)$ & 1.0 & 50.6 & $<0.001$ & 1.5 & 56.0 & & 0.2 & 81.8 & $<0.001$ & 0.3 & 119.6 & $<0.001$ \\
\hline $\mathrm{BF} \%$ middle tertile $(\mathrm{M} \geq 24.93-, \mathrm{F} \geq 36.37-\%$ of weight $)$ & 2.4 & & & 3.4 & & & 1.9 & & & 2.2 & & \\
\hline $\mathrm{BF} \%$ highest tertile $(\mathrm{M} \geq 31.36, \mathrm{~F} \geq 43.14 \%$ of weight $)$ & 7.4 & & & 9.6 & & & 7.1 & & & 9.7 & & \\
\hline
\end{tabular}

${ }^{a}$ For SSB, category 1-3 indicates lowest drinking frequency of "less often or never", 1-3 times per month or 1 time per week; category 4-6 indicates drinking frequency of 2-4, 5-6 times per week or 1 time per day, and category 7-9 indicates highest drinking frequency of 2-3, 4-5 or $\geq 6$ per day. For indices of adiposity, three sex-specific tertiles were created

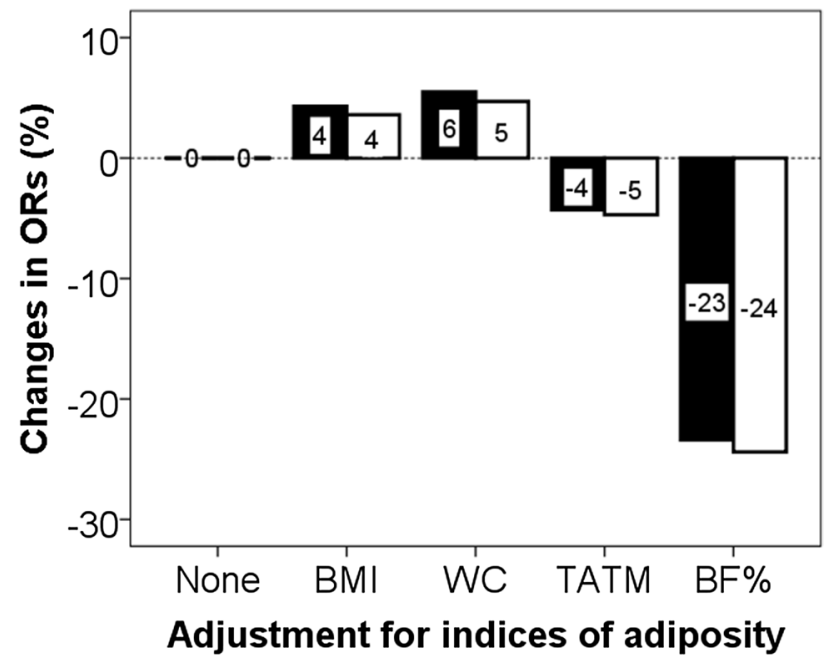

Fig. 1 Attenuation of the association between SSB and T2DM (solid bars) and between SSB and previously diagnosed T2DM+ no previous T2DM diagnosis with $\mathrm{HbA}_{1 \mathrm{c}}>6.5 \%$ (48 mmol/mol) (open bars) by different indices of adiposity indicated by the relative reduction of ORs
Numbers with complete data in this interesting group were too small for separate analysis.

\section{Discussion}

The present study shows that the weak association of SSB and T2DM, found fairly consistently in epidemiological studies, was changed marginally by BMI and WC but more markedly by better indices of body fat. Body fatness is, therefore important confounding factor, reflecting the complex interactions of SSB and caloric intake in the development of obesity and T2DM.

SSB consumption has previously been related to high BMI [15], particularly among adults aged under 45 years [16], which is supported by our results. Imamura et al. [12] conducted a meta-analysis of 17 studies comprising 38,253 cases with T2DM studied over 10,126,754 person years, mostly using food frequency questionnaires for dietary assessment. The positive association between SSB consumption and risk of T2DM was attenuated by BMI, indicated 
Table 3 Logistic regression analysis to assess relative changes in the association of SBB and previously diagnosed T2DM by indices of adiposity

\begin{tabular}{lllll}
\hline Predictor variables $^{\mathrm{a}}$ & \multicolumn{3}{l}{ Diagnosed T2DM $(n=172$ cases and 5015 non-cases $)$} \\
\cline { 2 - 5 } & OR & $95 \%$ CI & $p$ & $\begin{array}{l}\text { Relative changes in OR } \\
\text { by indices of adiposity } \\
(\%)\end{array}$ \\
\hline SSB 1-3 (referent) & 1 & - & - & - \\
SSB 4-6 & 1.19 & $0.48-2.96$ & 0.707 & - \\
SSB 7-9 & 2.56 & $1.12-5.83$ & 0.026 & 0 \\
SSB 1-3+ BMI (referent) & 1 & - & - & - \\
SSB 4-6+ BMI & 1.28 & $0.51-3.22$ & 0.594 & - \\
SSB 7-9+BMI & 2.67 & $1.16-6.14$ & 0.021 & +4.3 \\
SSB 1-3+ WC (referent) & 1 & - & - & - \\
SSB 4-6+ WC & 1.21 & $0.48-3.04$ & 0.683 & - \\
SSB 7-9+ WC & 2.70 & $1.07-5.60$ & 0.020 & +5.5 \\
SSB 1-3+ TATM (referent) & 1 & - & - & - \\
SSB 4-6+ TATM & 1.25 & $0.50-3.12$ & 0.639 & - \\
SSB 7-9+ TATM & 2.45 & $1.07-5.63$ & 0.035 & -4.3 \\
SSB 1-3+BF\% (referent) & 1 & - & - & - \\
SSB 4-6+BF\% & 1.07 & $0.43-2.68$ & 0.885 & - \\
SSB 7-9+BF\% & 1.96 & $0.85-4.49$ & 0.114 & -23.4 \\
\hline
\end{tabular}

All models were adjusted for age, sex, social class, education attainment, smoking status, alcohol consumption and physical activity level

aFor SSB, category 1-3 indicates lowest= "less often/never", 1-3 times/month or once/week; category 4-6 indicates intermediate $=2-4$ or $5-6$ times/week or once/day, and category 7-9 indicates highest intake $=2-3,4-5$ or $\geq 6 /$ day. Indices of adiposity and age were entered as continuous variables

${ }^{\mathrm{b}}$ Relative changes in OR by indices of adiposity were calculated by dividing (the difference between OR after adiposity adjustment and OR before adiposity adjustment) over OR before adiposity adjustment $\times 100 \%$, e.g. to calculate changes by BF\%: $[(1.96-2.56) / 2.56] \times 100 \%=-23.4 \%$ by a small reduction in relative risk from $1.18(95 \% \mathrm{CI}$ $1.09-1.28$ ) to 1.13 (95\% CI 1.06-1.21). Using our calculation method, this reduction represents $4.2 \%$ attenuation in the association between SSB and T2DM. Our present study found a little change after adjustment by BMI, WC (+4-6\%) or estimated TATM $(-4 \%)$, but substantially greater attenuation by estimated BF\% (-23\%).

BMI is frequently used as an indicator of adiposity and routinely recorded in large epidemiological studies [17]. However, BMI has only weak correlation with body fat, because BMI does not distinguish between body fat and muscle mass [18]. Thus, BMI explains only $60-70 \%$ of variance in percent body fat measured by reference techniques such as underwater weighing [7]. The present study found that BMI explained $72.4 \%$ of variance of BF\% as estimated by previous published equations [7], therefore, about $30 \%$ of residual variance from body fat remains to confound analyses. In slimmer, more muscular and younger populations, the relationship between BMI and body fat may be even weaker. WC, now also available in most health surveys, has a slightly better correlation with total body fat, as well as indicating body fat distribution [19]. We found both BMI and WC had minimal effect on the association between SSB and T2DM. We also examined BF\%, estimated by equations based again on simple measurements made in most health surveys [7, 14]. This provided the greatest attenuation, but these equations still only explain some $80 \%$ of variance in body fat, so the weakened remaining association between SSB consumption and T2DM includes substantial residual variance from body fat. The new estimates of body fatness using validated equations are preferable to BMI for other purposes.

The association of SSBs with health problems such as T2DM may be better explained by the modern patterns of eating, and snacking, which are characterised by high consumption of SSBs, than by the sugar itself. The current study is in line with this view. For decades, some have asserted fervently that sugar causes obesity and T2DM while others blamed artificial sweeteners for obesity and cancers without solid scientific evidence. During human evolution, the sweetest food we ever met_-except honey_-was human milk until the nineteenth century when unnaturally sweet drinks and sugary-fatty snacks were invented which had become abundant by the twentieth century. This sudden availability led to adverse effects, just as experimental animals fed "cafeteria diets" develop obesity and diabetes. Although glucose is an essential nutrient necessary for the function of every cell in our bodies, it is technically not essential in our diets, being readily generated from other foods. There are 
Table 4 Logistic regression analysis to assess changes in the association of SBB and previously diagnosed $\mathrm{T} 2 \mathrm{DM}+$ no previous T2DM diagnosis with $\mathrm{HbA}_{1 \mathrm{c}}>6.5 \%$ ( $48 \mathrm{mmol} / \mathrm{mol}$ ) by indices of adiposity

\begin{tabular}{|c|c|c|c|c|}
\hline \multirow[t]{2}{*}{ Predictor variables $^{\mathrm{a}}$} & \multicolumn{4}{|c|}{$\begin{array}{l}\text { Diagnosed T2DM }+ \text { no previous T2DM diagnosis with } \mathrm{HbA}_{1 \mathrm{c}}>6.5 \% \\
(48 \mathrm{mmol} / \mathrm{mol})(230 \text { cases and } 4957 \text { non-cases })\end{array}$} \\
\hline & OR & $95 \% \mathrm{CI}$ & $p$ & $\begin{array}{l}\text { Relative changes in OR } \\
\text { by indices of adiposity } \\
(\%)\end{array}$ \\
\hline SSB 1-3 (referent) & 1 & - & - & - \\
\hline SSB 4-6 & 1.34 & $0.66-2.70$ & 0.416 & - \\
\hline SSB 7-9 & 1.93 & $1.01-3.69$ & 0.046 & 0 \\
\hline SSB 1-3 + BMI (referent) & 1 & - & - & - \\
\hline SSB 4-6+BMI & 1.44 & $0.71-2.94$ & 0.314 & - \\
\hline SSB 7-9+BMI & 2.00 & $1.04-3.87$ & 0.038 & +3.6 \\
\hline SSB 1-3+WC (referent) & 1 & - & - & - \\
\hline SSB 4-6+WC & 1.36 & $0.67-2.77$ & 0.398 & - \\
\hline SSB 7-9+WC & 2.02 & $1.05-3.90$ & 0.035 & +4.7 \\
\hline SSB 1-3+ TATM (referent) & 1 & - & - & - \\
\hline SSB 4-6+TATM & 1.40 & $0.69-2.85$ & 0.354 & - \\
\hline SSB 7-9+ TATM & 1.84 & $0.96-3.54$ & 0.069 & -4.7 \\
\hline SSB 1-3+BF\% (referent) & 1 & - & - & - \\
\hline SSB 4-6+BF\% & 1.20 & $0.59-2.45$ & 0.611 & - \\
\hline SSB 7-9+BF\% & 1.46 & $0.76-2.82$ & 0.258 & -24.4 \\
\hline
\end{tabular}

All models were adjusted for age, sex, social class, education attainment, smoking status, alcohol consumption and physical activity level

${ }^{a}$ For SSB, category 1-3 indicates lowest= "less often/never", 1-3 times/month or once/week; category 4-6 indicates intermediate $=2-4$ or 5-6 times/week or once/day, and category 7-9 indicates highest intake $=2-3,4-5$ or $\geq 6 /$ day. Indices of adiposity and age were entered as continuous variables

${ }^{b}$ For calculations of attenuation, see footnote in Table 3 health benefits from sugar-containing fruits and vegetables, but sugar added during manufacturing confers no physical benefits. Added sugars have presented a reasonable target for taxation to raise revenue since the 1930s [20,21], now proposed explicitly against obesity [22].

The term "added sugars" can be confusing. They include "refined sugars" (either natural, from cane, or synthetic, made from grain or beet crops), but sweetness is also added to foods from natural sugar, from raisins, apple juice, honey, etc. All are biologically identical once inside the gut. Sucrose (table sugar) is a disaccharide comprising equal parts glucose and fructose. The fructose molecule is converted into glucose, our primary cellular nutrient. The evidence linking total, or added, sugar consumption with poor health is weak. Consumption of SSBs is more reliably estimated and so has a stronger evidence base for associations with poor health. SSBs contribute about $13 \%$ of total sugar intakes in the United Kingdom, up to $30 \%$ in children, but still below $5 \%$ of calories [23]. Reducing sugar in SSBs from 10 to $8 \%$ would affect about $0.4 \%$ of total calories, and under $1 \%$ even for the heaviest users. There are theoretical small benefits from sugar reduction, especially for those with very high intakes namely reducing blood pressure [24] and cardiovascular diseases [25]. If cutting down sugar intake can reduce weight gains by $2-3 \mathrm{~kg}$ [26], that would definitely help delay the onset of weight-related diseases like T2DM. There is no evidence, however, to support recommending a lower upper limit of sugar intake of a relatively generous $10 \%$ of calories. Systematic reviews and meta-analyses find no weight-independent effect of sugar on diabetes development $[5,26]$.

Two much-disputed bodies of evidence indicate that problems with obesity lie not with sugar or with sweeteners themselves, but with the modern eating patterns of snacking or grazing, which are marked by high consumption of both very sweet drinks and sugary/fatty snacks. First, a metaanalysis of randomized controlled and prospective cohort studies found absolutely no effect on body weight when sugar is replaced with the same calories from other carbohydrates [26]. Second, although evidence is conflicting [27], artificially sweetened drinks are also associated with weight gain [28]. It must be emphasised that this is only an association, but experimental animals only gain weight when both drinking water and foods are sweetened, either with sugar or with artificial sweeteners [29]. Human epidemiology can be explained by essentially the same story: both SSBs and artificially sweetened "diet" versions cause tolerance to unnatural sweetness, which promotes weight gain, mainly by promoting consumption of very sweet, energy-dense foods [5, 29]. "Reverse causality" may contribute; people with weight 
problems tend to choose diet drinks, but obese people prefer sweeter tastes and sweet, high-fat foods [30], and children who eat more fast foods prefer sweeter tastes [31].

The strengths of the present study lie in its relatively large homogeneous sample, with a wide range of SSB intakes and adiposity which enables us to reliably assess their relationships with T2DM, but the study has limitations. Causal links between SSB and T2DM cannot be established in this cross-sectional study, and there is some uncertainty the degree to which, under advice after diagnosis of T2DM, patients may have modified their 'diabetogenic' dietary habits [32, 33], particularly among ethnic minority groups [34]. In keeping with other published studies, some other factors were not available that could affect the association of SSB consumption and diabetes, such as dietary fat and fibre intake. The data available did not provide reliable quantitative assessment of dietary components, and estimation of total energy intake was not possible with the data collected. However, SSB consumption frequency has been assumed by most researchers to relate indirectly with quantitative intake, and has consistently been shown to associate with diabetes. In our study, indices of adiposity were derived from validated anthropometric measurements, rather than measured directly. This is in common with all large epidemiological studies, since these indices provide both practical and economical approach to assessment of adiposity; "direct" methods of measuring adiposity such as magnetic resonance imaging are too expensive and time consuming to both investigators and participants, and there is no evidence that other indirect methods such as bioimpedance are better than anthropometric estimates [19].

In conclusion, the association between SSB and T2DM is changed by adiposity, most markedly by \%body fat, indicating the importance of adjustment for body fatness using validated equations such as those published by Lean et al. [7] and Al-Gindan et al. [14], rather than just BMI, in future research in this area.

Author contributions All co-authors contributed to the study design, analyses and interpretation, and manuscript writing.

\section{Compliance with ethical standards}

Conflict of interest The authors declare no conflicts of interest.

Open Access This article is distributed under the terms of the Creative Commons Attribution 4.0 International License (http://creativeco mmons.org/licenses/by/4.0/), which permits unrestricted use, distribution, and reproduction in any medium, provided you give appropriate credit to the original author(s) and the source, provide a link to the Creative Commons license, and indicate if changes were made.

\section{References}

1. World Health Organization (2016) Global report on diabetes. WHO Press, Geneva

2. Forouzanfar MH, Alexander L, Anderson HR et al (2015) Global, regional, and national comparative risk assessment of 79 behavioural, environmental and occupational, and metabolic risks or clusters of risks in 188 countries, 1990-2013: a systematic analysis for the Global Burden of Disease Study 2013. Lancet 386:2287-2323

3. Torgerson JS, Hauptman J, Boldrin MN, Sjöström L (2004) XENical in the prevention of diabetes in obese subjects (XENDOS) study: a randomized study of orlistat as an adjunct to lifestyle changes for the prevention of type 2 diabetes in obese patients. Diabetes Care 27:155-161

4. Tuomilehto J, Lindström J, Eriksson JG; Finnish Diabetes Prevention Study Group et al (2001) Prevention of type 2 diabetes mellitus by changes in lifestyle among subjects with impaired glucose tolerance. N Engl J Med 344:1343-1350

5. Lean ME, Te Morenga L (2016) Sugar and type 2 diabetes. $\mathrm{Br}$ Med Bull 120:43-53

6. Basu S, Yoffe P, Hills N, Lustig RH (2013) The relationship of sugar to population-level diabetes prevalence: an econometric analysis of repeated cross-sectional data. PLoS One 8:e57873

7. Lean ME, Han TS, Deurenberg P (1996) Predicting body composition by densitometry from simple anthropometric measurements. Am J Clin Nutr 63:4-14

8. Braam LA, Ocké MC, Bueno-de-Mesquita HB, Seidell JC (1998) Determinants of obesity-related underreporting of energy intake. Am J Epidemiol 147:1081-1086

9. Heerstrass DW, Ocké MC, Bueno-de-Mesquita HB et al (1998) Underreporting of energy, protein and potassium intake in relation to body mass index. Int J Epidemiol 27:186-193

10. Kvaavik E, Andersen LF, Klepp KI (2005) The stability of soft drinks intake from adolescence to adult age and the association between long-term consumption of soft drinks and lifestyle factors and body weight. Public Health Nutr 8:149-157

11. Mourao DM, Bressan J, Campbell WW, Mattes RD (2007) Effects of food form on appetite and energy intake in lean and obese young adults. Int J Obes 31:1688-1695

12. Imamura F, O'Connor L, Ye Z et al (2016) Consumption of sugar sweetened beverages, artificially sweetened beverages, and fruit juice and incidence of type 2 diabetes: systematic review, meta-analysis, and estimation of population attributable fraction. Br J Sports Med 50:496-504

13. Scottish Health Survey, 2010 NHS Health Scotland (2010) Questionnaires and showcards. UK Data Archive Study Number 6987-a survey carried out on behalf of The Scottish Government Health Directorates and NHS Health Scotland. Scottish Centre for Social Research Department of Epidemiology and Public Health, University College London and The MRC Social and Public Health Sciences Unit, Glasgow

14. Al-Gindan YY, Hankey CR, Govan L et al (2015) Derivation and validation of simple anthropometric equations to predict adipose tissue mass and total fat mass with MRI as the reference method. Br J Nutr 114:1852-1867

15. Ruanpeng D, Thongprayoon C, Cheungpasitporn W, Harindhanavudhi T (2017) Sugar and artificially-sweetened beverages linked to obesity: a systematic review and meta-analysis. QJM 110:513-520

16. Singh GM, Micha R, Khatibzadeh S, Shi P; Global Burden of Diseases Nutrition and Chronic Diseases Expert Group (NutriCoDE) et al (2015) Global, regional, and national consumption of sugar-sweetened beverages, fruit juices, and milk: a 
systematic assessment of beverage intake in 187 countries. PLoS One 10:e0124845

17. O'Connor L, Imamura F, Lentjes MA et al (2015) Prospective associations and population impact of sweet beverage intake and type 2 diabetes, and effects of substitutions with alternative beverages. Diabetologia 58:1474-1483

18. Al-Gindan YY, Hankey C, Govan L et al (2014) Derivation and validation of simple equations to predict total muscle mass from simple anthropometric and demographic data. Am J Clin Nutr 100:1041-1051

19. Han TS, Lean MEJ (2002) Anthropometric indices of obesity and regional distribution of fat depots, chap. 4. In: Björntorp P (ed) International textbook of obesity, 1st edn. Wiley, Chichester, pp 51-65

20. Wolf HA (1959) Sugar: excise taxes, tariffs, quotas, and program payments. South Econ J 25:416-424

21. Snape RH (1969) Sugar: costs of protection and taxation. Econ New Ser 36:29-41

22. Jensen JD, Smed S (2007) Cost-effective design of economic instruments in nutrition policy. Int J Behav Nutr Phys Act 4:10

23. Public Health England and Food Standards Agency. NDNS: Results from Years 1, 2, 3 and 4 (combined) of the RP (2014) https://www.gov.uk/government/statistics/national-diet-and-nutri tion-survey-results-from-years-1-to-4-combined-of-the-rollingprogramme-for-2008-and-2009-to-2011-and-2012. Accessed 23 Jan 2017

24. Te Morenga L, Howatson AJ, Jones RM, Mann JI (2014) Dietary sugars and cardiometabolic risk: systematic review and metaanalyses of randomized controlled trials of the effects on blood pressure and lipids. Am J Clin Nutr 100:165-179

25. Warfa K, Drake I, Wallström p, Engström G (2016) Association between sucrose intake and acute coronary event risk and effect modification by lifestyle factors: Malmö Diet and Cancer Cohort Study. Br J Nutr 116:1611-1620

26. Te Morenga L, Mallard S, Mann J (2012) Dietary sugars and body weight: systematic review and meta-analyses of randomised controlled trials and cohort studies. BMJ 346:e7492

27. Miller PE, Perez V (2014) Low-calorie sweeteners and body weight and composition: a meta-analysis of randomized controlled trials and prospective cohort studies. Am J Clin Nutr 100:765-777

28. Brown RJ, de Banate MA, Rother KI (2010) Artificial sweeteners: a systematic review of metabolic effects in youth. Int J Pediatr Obes 5:305-312

29. Fowler SP (2016) Low-calorie sweetener use and energy balance: results from experimental studies in animals, and large-scale prospective studies in humans. Physiol Behav 164:517-523

30. Drewnowski A, Brunzell JD, Sande K et al (1985) Sweet tooth reconsidered: taste responsiveness in human obesity. Physiol Behav 35:617-622

31. Lee SS (2004) A study on dietary behavior of children according to their preferences for fast food. Korean J Community Nutr 9:204-221

32. Wing RR, Goldstein MG, Acton KJ et al (2001) Behavioral science research in diabetes: lifestyle changes related to obesity, eating behavior, and physical activity. Diabetes Care 24:117-123

33. Peel E, Parry O, Douglas M, Lawton J (2005) Taking the biscuit? A discursive approach to managing diet in type 2 diabetes. J Health Psychol 10:779-791

34. Lawton J, Ahmad N, Hanna L et al (2008) 'We should change ourselves, but we can't': accounts of food and eating practices amongst British Pakistanis and Indians with type 2 diabetes. Ethn Health 13:305-319 